\title{
Examining the Success and Failure Factors of Business Process Reengineering in Africa, Asia, the Middle East, and North America: A Literature Review
}

\author{
Kathryn Virzi \\ Graduate School of Business and Management, Fremont College, Cerritos, CA, USA \\ Email: kathryn_virzi@yahoo.com
}

How to cite this paper: Virzi, K. (2019) Examining the Success and Failure Factors of Business Process Reengineering in Africa, Asia, the Middle East, and North America: A Literature Review. Open Access Library Journal, 6: e5722.

https://doi.org/10.4236/oalib.1105722

Received: August 22, 2019

Accepted: September 21, 2019

Published: September 24, 2019

Copyright $\odot 2019$ by author(s) and Open Access Library Inc.

This work is licensed under the Creative Commons Attribution International License (CC BY 4.0).

http://creativecommons.org/licenses/by/4.0/

(c) (i) Open Access

\begin{abstract}
Using business process reengineering (BPR) to effectively implement new strategic initiatives and integrate new technology can radically upgrade organizations (Dachyar, Yadrifil \& Pratama, 2015). The following literature review compares empirical studies from eight different countries (including the United States) to identify global commonalities and differences of Business Process Reengineering (BPR) practices and the Integration of technology in the areas of research interest, critical success factors, and failure factors and recommendations. Information gathered is synthesized using a cross-cultural comparison with the eight evaluated countries divided by continent. To ensure complete understanding, term definitions and an explanation of the topic's importance are included. In addition, a brief description of each study's methodology is described in the section on research interest, and comparison findings are discussed at the end. (Key terms are provided that they are after the references.)
\end{abstract}

\section{Subject Areas}

Case Studies and Management Information Systems

\section{Keywords}

Business Process Reingeering (BPR), Enterprise Resource Planning (ERP)

\section{Importance of Topic}

Not much research has been done on the effects of BPR implementation or business related technology integration in developing countries [1]. Recent re- 
search reflects a growing interest in the study and implementation of BPR, particularly on a global level. A great deal of empirical evidence on BPR has been collected over the past 10 years that span across both continents and industries to identify BPR success and failure factors, but global comparisons of findings and recommendations are scarce. Technology plays a large role in BPR and provides unique opportunities for innovation and effectiveness, but it can be costly, underused, and frustrating for employees [2]. Finally, although results have indicated the success rates of BPR, there is also a large number of reported failure [3]. A close comparison of studies done throughout varying countries and industries will provide added insight to BPR and technology related factors.

\section{Research Collected by Region}

To present a thorough review of BPR commonalities and differences among varying countries, a brief description of the purposes and methodologies of the eight empirical studies is provided. The countries are grouped together by continent and include Africa, Asia, the Middle East, and North America. Each subsection provides information on studies from two or three different countries with the exception of North America, which only includes one study from the United States.

\subsection{Africa}

Two empirical studies were recently completed in Africa to investigate the success and failure factors of BPR implementation. Last year, 402 surveys completed by senior level managers in Nigeria were collected to identify the critical success factors of BPR and to discover their effects on operational and organizational performance in the country's petroleum industry [1]. In Uganda, an investigation on the possible BPR failure factors of the country's organizations was completed through the collection of 150 validated surveys from five different organizations [2].

\subsection{Asia}

Three empirical studies focusing on IT related factors of BPR are presented. The relationship between organizational innovation models and information systems on strategic innovation among higher educational institutions was examined in Indonesia by gathering quantifiable research from 961 approved questionnaires that were completed by employees from three of the country's top universities located in Jakarta, Bandung and Bogor [4]. In an attempt to improve the effectiveness of ERP system use in Japanese firms, 197 surveys were collected from IT leaders who worked in firms where ERP had been implemented. These surveys measured the degree of satisfaction among Japanese ERP implementation structures [5]. To create awareness of the important role that BPR plays in the need to the meet user demands of library systems, a three year reengineering project was developed, implemented and analyzed at the National Institute of Science 
Communication and Information Resources in India [6].

\subsection{Middle East}

To aid in the development of BPR best practices, two empirical studies were completed. In Iran, a mixed method model was used to measure factors relating to change tolerance in reengineering projects. Forty surveys were collected from BPR experts, and 15 business professionals with at least 5 years of management experience were interviewed. The purpose of the study was to gather data that would aid in the development of best practices for BPR to achieve lower risk and reduce failure rates [7]. In Kurdistan, a comprehensive analysis of BPR practices among small to medium industrial firms was done in an attempt to find best BPR methods to improve production and service in developing countries. Several Kurdistan firms were evaluated through direct observation, interviews, and the study of work processes. An unidentified number of questionnaires were also collected from stake holders [8].

\subsection{North America}

In the United States, quantitative data was collected from 212 top multinational plant managers to investigate varying aspects of BPR success factors of processing at the project level [3]. The questionnaire was developed based on extensive literature and measured perceived success factors on varying phases of the implementation process.

\section{Critical Success Factors}

A successful BPR can bring competitive advantage and organizational growth to an organization [1]. This section looks at the critical success factors discussed or discovered in each article through a cross-cultural lens. A comparison of findings is discussed in a later section.

\subsection{Africa}

The focus of the study on the Petroleum Industry in Nigeria was the impact of BPR critical success factors (CSFs) on operational and organizational performance. Asikhia and Awolusi [1] compiled a list of 32 CSFs were determined through a compilation of findings in literature. The overall themes of the list are threefold. The first is the importance of inclusion. This is achieved through education, training, input, and communication. The second is the need to implement updated and adequate IT systems into the infrastructure of the overall BPR plan. The last is the importance of the manager's role in his or her understanding of possible risks that may stem from the project as well as the need for continued evaluation and adjustment. It was concluded that successful BPR can improve both the productivity and customer satisfaction.

Mlay et al. [2] used a logistics model to combine and weigh various CSRs listed in literature. It was concluded that the CSRs with the strongest impact are 
1) a positive emotional response to $\mathrm{BPR}, 2$ ) complete understanding of IT user requirements, and 3) managers' understanding of the implementation, communication and challenges that come with BPR.

\subsection{Asia}

Dachyar et al. [4] based an entire empirical study on the agreement that ERP and BPR add great benefit to any organization, but only if it is coupled with the introduction of new concepts and the establishment of objectives that stem from the strategic innovation that come with the implementation of ERP and BPR.

The aim of Kayo et al's study [5] was to find ways to improve the effectiveness of ERP system implementation. Because BPR is the framework used to execute new ERP systems, the study interlinked ERP and BPR success factors relating them more to the success of IT related implementation. Three primary factors attributed to the successful implementation of ERP through BPR. The first CSR is that an organization must be prepared for the fundamental change that the new process will bring. The second is the competency of the project manager in terms of goal setting, communication, and IT training abilities. The third is cooperation satisfaction, but this is only a success factor when operational satisfaction is achieved. Ultimately, it was found that the key to successful ERP is the use of BPR to implement IT.

Natarajan [6] noted several CSF all related to human factors. These included having an organizational culture that is comfortable with change, as well as having a management that provides inclusion, empowerment, effective communication and training. Although the focus of the study was to create awareness of the important role that BPR plays in meeting user demands of library software and other IT systems, the success factors hinged on the human aspect of organizational restructuring.

\subsection{Middle East}

Darmani and Hanafizadeh [7] concluded from their research that reengineering success comes from the selection phase of the strategic process. Specific tasks mentioned that play a crucial role in success include deciding on what strategy to use, defining and evaluating risk and return of the project implementation, and choosing the frames for differentiation, cost leadership and response methods.

In an effort to find the best BPR methods for improving production and service in developing countries, Farughi et al. [8] concluded that CSF should be defined at each process level and customized evaluation measures should be developed for each CSF. In essence, success factors of BPR are individualized and should be measured based on the organization's unique characteristics.

\subsection{North America}

The large percentage of reported BPR related failure prompted Guimaraes and 
Paranjape [3] to examine CSFs in practical application settings of organizations. Using 19 CSFs determined from gathered literature. The main themes in the factors listed revolved around strong project leadership, good communication across all levels of the organization, competent and positive IT personnel, and careful planning for all aspects of the project before implementation. The results of the study indicated that CSF varied among companies and project phase. Also, it was discovered that many CSFs are dependent on the outcomes of preceding phase.

\section{Failure Factors and Recommendations}

The primary reasons for conducting research surrounding BPR and technology integration are to discover best practices, uncover explanations for failure, and develop strategies to enhance or correct the process [3]. The identified failure factors of both BPR and other process related strategies are discussed below along with recommendations made by each examined country.

\subsection{Africa}

In Africa, many organizations that use BPR to enhance operations do not achieve the desired results. This is attributed to incorrect implementation and not the process itself. Failure factors include a company's lack of commitment to maintain strong lines of communication throughout the process, and a lack of knowledge about the company's structure. It was determined that technology issues are really people issues and must be managed that way [3].

Resistance to change is the biggest failure factor in BPR and new IT implementation in Africa. The results of Mlay et al's study uncovered that resistance to implementing new IT software stems from low competence levels of users, leadership that is overly cautious about investing in a new IT project, and fear of layoffs resulting from the new initiative. Failure factors have been largely equated to human factors in Africa and the need for company-wide inclusion of the project, and open communication on all levels was expressed [2].

\subsection{Asia}

It was concluded in Asia that organizational change brought on by ERP and BPR implementation is the biggest contributing factor to organizational innovation and performance. However, these processes tend to occur only among entities that have the resources needed to develop new technology. The focus of this study was not on success or failure factors of BPR, but rather an argument showing the positive impacts of ERP and BPR implementation on achieving organizational innovation, longevity, and a competitive advantage. In that regard, a lack of resources would be considered a failure factor in that it hinders initial implementation [4].

The two failure factors considered by Kayo et al. [5] were both listed as cultural considerations and not failure factors. The first was Japan's unique man- 
agement style of lifetime employment and bottom-up decision making. Because hiring someone for the extent of their lifetime is common practice in Japanese companies, short-term or external IT professionals are not easy to find. The bottom-up practice focuses on compromise and mutual understanding, thus weakening the decision-making process. The second obstacle presented was Japan's tendency to use customized software. The empirical findings of the study confirmed that less customized software and strong BPR management are of crucial importance to successful implementation.

Natarajan [6] listed 23 problems that libraries have in relation to implementing new IT systems. These included lack of training, low resources, improper IT integration, communication problems, resistance to change, inadequate focus, and undefined objectives. The proposed solution was to use BPR for the implementation of IT integration, but no failure factors of BPR were presented.

\subsection{Middle East}

From their study, Darmani and Hanafizadeh [7] found several factors that hindered BPR processes. A lack of adequate training and missteps in process selection and communication were viewed as failure factors. The authors also discovered that there is a threshold point that is considered to be the point of maximum tolerance for the degree of change. Once past this point, the risk of failure is magnified. The authors developed a new reengineering model call the Business Process Portfolio Selection (BPPS). This model is a hybrid of BPR combined with concepts used to reduce portfolio selection problems.

Farughi et al. [8] looked at problems that arise from being an organization in a developing country such as old or unusable software, internet connectivity issues, misuse of software, and a lack of education and training. BPR failure factors were not identified, rather BPR was put forth as a means for identifying current problems in IT, operations and the execution process. BPR would also be used to create a plan to implement change by determining the company's CSFs and providing an evaluation tool to measure progress and make recommendations as needed.

\subsection{North America}

It was determined that a large failure factor of BPR in the U.S. comes from managers who do not take all advice prescribed to ensure BPR success. Other failure factors include a lack of IT support and weak project leadership. Recommendations made based on the outcome of the study were to provide strong and motivating project leadership, make sure the company has a strong start, and provide effective IT support throughout the entire process [3].

\section{Comparison Findings}

In review of the literature, several comparisons were discovered. When evaluating the purpose of each study, there were commonalities within continents. Both 
African studies looked at success and failure factors of BPR, while all three Asian countries focused on finding best practices for implementation of both ERP and BPR. The two studies done in the Middle East had an emphasis on finding ways to improve BPR. The purpose of the US study was most closely aligned with Africa and the Middle East in terms of evaluating CSFs and looking to discover ways to improve BPR implementation.

All countries obtained their definitions of CSFs from past literature and show no significant differences or discrepancies in their findings. However, to what level the information obtained on CSFs was used in the study was based on the focus of each individual study and seems to be unrelated to factors relating to country or culture.

There were some dividing commonalities among failure factors. All of the developing countries except for those in Africa attributed failure to a lack of training, resources, and education. Both African countries said human factors are $100 \%$ responsible for the failure of BPR implementation. Five of the 8 studies spoke about resistance to change, and there were three failure factors that were recorded by all 8 studies across the board, namely communication problems, poor project management, and a myriad of IT related issues.

Finally, commonalities in recommendations can be divided into three categories. The three studies from Asia all recommended using BPR to implement ERP or other software programs. All other countries recommended continued use of BPR, but with recommendations for modification. Both African studies recommended that companies focus on correcting the human factors in BPR and not the process. Iran recommended a new process model called BPPR which incorporates a component to $\mathrm{BPR}$ that measures risk and return on project investment. Both the US and Kurdistan discussed the need for the customization of CSFs at each project phase and the development of individualized measuring tools for continued evaluation.

\section{Conclusion}

To identify global commonalities and differences of Business Process Reengineering (BPR) practices and the Integration of technology in the areas of research interest, critical success factors, and failure factors and recommendations, empirical studies from eight different countries (including the United States) were synthesized using a cross-cultural comparison divided by continent. Several commonalities were discovered within continents, among developing countries, and across the board. One conclusion that has remained intact is that utilizing BPR to implement new strategies and integrate new technology is a recommended strategy for success.

\section{Conflicts of Interest}

The author declares no conflicts of interest regarding the publication of this paper. 


\section{References}

[1] Asikhia, U. and Awolusi, D. (2015) Assessment of Critical Success Factors of Business Process Re-Engineering in the Nigerian Oil and Gas Industry. South African Journal of Business Management, 46, 1-14. https://doi.org/10.4102/sajbm.v46i2.87

[2] Mlay, S.V., Zlotnikova, I. and Watundu, S. (2013) A Quantitative Analysis of Business Process Reengineering and Impacting Factors: The Case of Uganda. African Journal of Information Systems, 5, 1-26.

[3] Guimaraes, T. and Paranjape, K. (2013) Testing Success Factors for Manufacturing BPR Project Phases. International Journal of Advanced Manufacturing Technology, 68, 1937-1947. https://doi.org/10.1007/s00170-013-4809-0

[4] Dachyar, M., Yadrifil and Pratama, N.R. (2015) Development of Strategy Model for Organizational Innovation through Information Systems in Higher Education in Indonesia. International Journal of Technology, 6, 284.

https://doi.org/10.14716/ijtech.v6i2.659

[5] Kayo, I., Yutaka, T., Ruri, N. and Chihiro, S. (2014) Satisfaction Structure of the Implementation Effect of Enterprise Resource Planning (ERP): An Analysis from the Management Style Perspective of Japanese Firms. International Journal of Business \& Information, 9, 273-310.

[6] Natarajan, M. (2009) Exploring the Business Process Re-Engineering: National Science Library's Experience. Communications of the IIMA, 9, 85-91. https://scholarworks.lib.csusb.edu/cgi/viewcontent.cgi?article=1123\&context=ciima

[7] Darmani, A. and Hanafizadeh, P. (2013) Business Process Portfolio Selection in Re-Engineering Projects. Business Process Management Journal, 19, 892-916. https://doi.org/10.1108/BPMJ-08-2011-0052

[8] Farughi, H., Alaniazar, S. and Mousavipour, S.H. (2014) Presenting a Framework of Reengineering Methodology for Organizational Diagnosis and Process Improvement (Case Study: Industrial Estate Company of Kurdistan). International Journal of Management, Accounting \& Economics, 1, 295-310. 


\section{Definitions of Terms}

Central terms that appear frequently in the Literature are as follows:

Business Process Reengineering (BPR): A structured evaluation and implementation of strategy, process, technology, organization, and culture. (Mlay, Zlotnikova, and Watundu, 2013)

Critical success factors (CSF): Structural decisions made by managers that are known to produce positive results with the implementation of BPR (Guimaraes \& Paranjape, 2013)

Failure factors: Primary reasons that lead to failed BPR efforts in an organization (Darmani \& Hanafizadeh, 2013)

Developing countries: A country that is considered among poorer countries of the world but is working to become more economically and socially advanced (Farughi, Alaniazar, \& Mousavipour, 2014)

Enterprise Resource Planning (ERP): A type of business-management software frequently used in BPR (Kayo, Yutaka, Ruri, \& Chihiro, 2014)

Information technology (IT): Any technology related product or service (Mlay et al., 2013) 